\title{
Three cases of early-stage localised Lyme disease
}

\author{
Mahizer Yaldiz ${ }^{*}$, MD, Teoman Erdem¹, MD, Fatma H Dilek², MD
}

${ }^{1}$ Department of Dermatology, '2Department of Pathology, Sakarya University Training and Research Hospital, Sakarya 54010, Turkey

*Corresponding author: drmahizer@gmail.com

Hong Kong Med J 2017;23:204-6

DOI: 10.12809/hkmj144416

\section{Case reports}

\section{Case 1}

A 6-year-old girl was referred to our hospital in July 2010 with a red patch on one leg. The red patch had appeared 15 days after a tick-bite and become increasingly large within the last 1.5 months. Dermatological examination revealed an irregular annular erythema of $10 \times 15 \mathrm{~cm}$, with ecchymotic centre and pale outer edge on the anteromedial part of her left thigh (Fig a). Systemic examination as well as complete blood picture and liver and renal function tests were normal. In view of the history of tick-bite and prediagnosis of erythema chronicum migrans (ECM), Borrelia burgdorferi serology was requested and confirmed positive immunoglobulin (Ig) $\mathrm{M}$ to $B$ burgdorferi. A diagnosis of Lyme disease was considered and treatment was started with amoxicillin and clavulanic acid at a paediatric dose of $50 \mathrm{mg} / \mathrm{kg} /$ day. After 15 days, the patient showed clinical improvement and at 6-month follow-up there were no systemic findings.

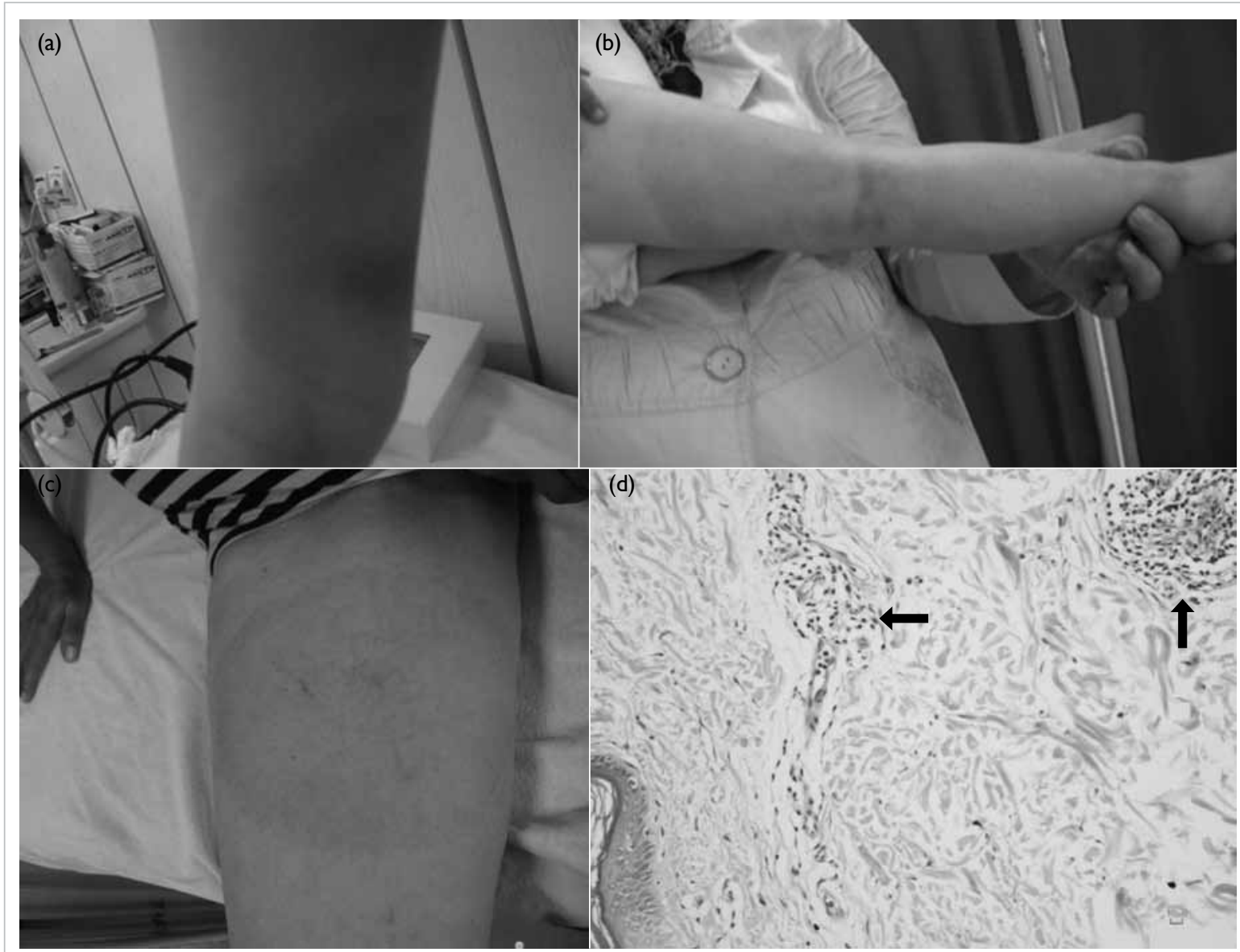

FIG. (a) Case I: an irregular annular erythema of $10 \times 15 \mathrm{~cm}$ with ecchymotic centre and pale outer edge on the anteromedial part of the left thigh. (b) Case 2: an irregular annular erythema with pale centre starting from around the crust corresponding to the point of tick-bite on the right knee and extending from the foot ankle to the lower third part of the thigh. (c) Case 3: an irregular annular erythema of size $5 \times 7 \mathrm{~cm}$ with pale centre on the anteromedial part of the right thigh. (d) Case 3: superficial and deep perivascular lymphoplasmocytic inflammatory cell reaction and swollen endothelial cells in the superficial and deep dermis (arrows) [H\&E; original magnification, $x$ 40] 


\section{Case 2}

A 2-year-old girl was referred to our hospital in May 2010 with a red patch on one leg that developed 10 days after a tick-bite and became increasingly large. Dermatological examination revealed an irregular annular erythema with pale centre starting from around the crust corresponding to the tick-bite on her right knee and encompassing an area from the ankle to the lower third of the femur (Fig b). Systemic examination was normal as were complete blood picture and liver and renal function tests. Borrelia burgdorferi serology was not performed. Lyme disease was considered and treatment was started with amoxicillin-clavulanic acid at a paediatric dose of $50 \mathrm{mg} / \mathrm{kg} /$ day. The patient showed clinical improvement after 15 days and there were no systemic findings at 6-month follow-up.

\section{Case 3}

A 53-year-old female patient was referred to our hospital in June 2010 with a red patch on her right leg that developed about 1 month previously and had steadily enlarged over the preceding 10 days. She had been bitten by a tick in the same region approximately 1.5 months earlier. Dermatological examination revealed an irregular annular erythema of about 5 $\mathrm{x} 7 \mathrm{~cm}$ with pale centre on the anteromedial part of her right thigh (Fig c). Systemic questioning and examination was normal and B burgdorferi serology, IgM, and IgG were negative. Histopathological examination of a skin biopsy revealed a perivascular lymphoplasmocytic inflammatory cell reaction and swelling of the endothelial cells in the superficial and deep dermis. The findings were consistent with ECM (Fig d). In view of the anamnesis and clinical and histopathological findings, the case was diagnosed as Lyme disease. Treatment was started with oral doxycycline (100 mg twice daily for 2 weeks). Followup at 15 days showed clinical improvement and the patient had no systemic findings after 6 months.

\section{Discussion}

Lyme disease is a systemic disorder that can affect many organs and is caused by some Borrelia species transmitted by the Ixodes genus of ticks. There are three genotypes of Borrelia that cause Lyme disease in humans: Borrelia burgdorferi sensu strico, Borrelia afzelii, and Borrelia garinii, collectively known as Borrelia burgdorferi sensu lato. Vector-transmitted Lyme infection is frequently seen in the United States and Europe. ${ }^{1-7}$

In Turkey, the disease was first reported in 1990 in the Black Sea and Aegean Regions of the country. To date, 25 types in the family Ixodidae have been reported in Turkey. ${ }^{1-9}$ Ixodes ricinus may be seen in all geographical areas of the country but is particularly widespread in humid forest areas (Black Sea, Marmara, and Mediterranean regions). The definitive prevalence of $B$ burgdorferi infection in Turkey is unknown because of limited investigations. Seropositivity in the general population has been reported as $2 \%$ to $6 \%$ and in risk groups in endemic region as $6 \%$ to $44 \%$, but values change with different country regions. ${ }^{10-14}$ Lyme disease is seen in both genders and in all age-groups, but is more prevalent in adults aged between 30 and 59 years and in children under 15 years of age. ${ }^{13}$ Approximately 60 cases have been reported in Turkey since 1990 . When children were analysed, approximately $48 \%$ had a history of tick retention and most of the skin lesions were identified (approximately $46 \%$ in early stage). Neuroborreliosis is the second common clinical form to be reported. The Lyme disease is more common in women (70\%) and the age distribution is 4 to 72 years (mean, 29.1 years); cases are mostly seen between March and July when vectors (nymphs) are active. ${ }^{15}$

Erythema chronicum migrans is the most frequently seen and most important diagnostic skin lesion in Lyme disease. ${ }^{3,6,7}$ It occurs on any part of the body and appears at the site of a tick-bite after an incubation period of 3 to 32 days, depending on the migration of spirochaetes in the skin. The incubation period can extend to 6 months, however., ${ }^{3,7}$ The lesion that starts as a red macule or papule rapidly expands outwards. It will then turn pale in the centre and develop into an annular rash, giving the appearance of a target board or bull's eye. ${ }^{7,13}$ The diameter of the lesion varies between $4 \mathrm{~cm}$ and $60 \mathrm{~cm}$. The lesion should have a minimal diameter of $5 \mathrm{~cm}$ in order to be defined as ECM. Local symptoms such as a burning sensation, itching, or pain may be reported. ${ }^{7,11}$

Following primary infection, the acute disseminated stage starts with dissemination of the causative agent to other tissues via blood and lymph vessels. The skin findings at this stage of infection include secondary ECM, borrelial lymphocytoma, urticarial plaques, erythema nodosum, and a malar rash. ${ }^{3,14}$ Secondary ECM lesions occur at sites distant from the tick-bite and will range in number from 2 to 30. The initial ECM may be followed by similar but generally smaller and often non-migrating lesions. More than 10 lesions are uncommon, but may occur. ${ }^{3,4,7}$ Borrelial lymphocytoma presents as a solitary bluish-red soft nodule with a slightly atrophic surface that varies from 1 to $5 \mathrm{~cm}$ in diameter, and occurs most frequently on the earlobe, nipple, scrotum, or axillary region. In this stage of dissemination, cardiac, neurological, and joint findings predominate. , $^{1,4,7}$

After several months or years, untreated patients may go on to develop late-stage Lyme disease. Acrodermatitis chronica atrophicans is the characteristic skin lesion in this stage. Other 
findings are of mono- or oligo-arthritis, meningoencephalitis, and uveitis. This stage may be the result of an immunopathological process in the absence of clinical regression with antibiotic therapy, a chronic inflammatory response, and no isolation of the causative bacterium from the lesions. ${ }^{2-4,7,12}$ The three cases reported here showed only an ECM lesion and no systemic findings at 6-month follow-up. This was consequent to adequate therapy commenced at an early stage of the disease.

The diagnosis of Lyme disease is based on symptoms, objective physical findings (ECM, facial paralysis, arthritis, etc), and a history of tick contact. ${ }^{1,4,9}$ The results of enzyme-linked immunosorbent assay and Western blot analysis can be used to support the diagnosis., ${ }^{4,9}$ The diagnosis of early-stage Lyme disease is based on the presence of ECM and history of tick-bite. ${ }^{3,6,7}$ Since the rate of false-negative results is high in the acute stage of the disease, serological tests are not recommended, but are used to support the clinical findings of early- and late-disseminated stages of Lyme disease. ${ }^{8-12}$ Our case 1 confirmed positive IgM to $B$ burgdorferi. Case 2 underwent no serological tests. In case 3, both IgM and IgG were negative to $B$ burgdorferi.

Skin biopsy is used for the differential diagnosis of ECM. In ECM cases, there is a patchlike perivascular mononuclear infiltration of the superficial and deep dermis. This infiltration consists of predominantly lymphocytes and histiocytes as well as plasma cells in varying quantities. ${ }^{3,7,11}$ In our case 3, histopathological examination of her skin biopsy for differential diagnosis demonstrated perivascular lymphoplasmocytic inflammatory cell infiltration in the superficial and deep dermis. This histopathological picture supported our diagnosis of ECM.

Doxycycline, amoxicillin, and cefuroxime axetil are the antibiotics of choice. The recommended duration of therapy for early-stage disease is 14 to 21 days and for late stage at least 4 weeks., ${ }^{4,72}$ Since our first two cases were children, they received amoxicillin and clavulanic acid $50 \mathrm{mg} / \mathrm{kg} / \mathrm{day}$ for 15 days. Our case 3 was an adult and received oral doxycycline (100 mg twice daily for 2 weeks). At 15 days, all lesions were completely cured in all patients, and there was no relapse or systemic involvement at 6-month follow-up.

In conclusion, ECM is an important clinical sign of early-stage Lyme disease. The diagnosis and therapy of Lyme disease at an early stage is vital as it prevents progression to late-stage disease. In endemic regions and in patients with a history of tick-bite, the clinician should stay alert to the presence of ECM. If a patient is considered to have ECM, specific investigations for Lyme disease should be ordered.

\section{References}

1. Winn WJ, Allen S, Janda W. Spirochetal infections. Koneman's color atlas and textbook of diagnostic microbiology. 6th ed. Philadelphia: Lippincott Williams and Wilkins; 2006: 1135-43.

2. Mullegger RR. Dermatological manifestations of lyme borreliosis. Eur J Dermatol 2004;14:296-309.

3. Topcu AW, Soyletir G, Doğanay M, Doğanci L. Lyme disease: infectious diseases and microbiology. 3. Istabul: Nobel Tip Kitapevleri; 2008: 973-88.

4. Borriello SP, Murray PR, Funke G. Postic D. Borrelia. Topley and Wilson's microbiology and microbial infections. 10th ed. London: Hodder Arnold; 2005: 1818-37.

5. Wolff K, Goldsmith LA, Katz SI, Gilchrest BA, Paller AS, Leffel DJ. In: Mahalingam M, Bhawan J, Chomat AM, Hu L. Lyme borreliosis. Fitzpatrick's dermatology in general medicine. 7th ed. New York: McGraw Hill; 2008: 1797-806.

6. Tepe B, Sayiner HS, Karincaoğlu Y. Early stage localized Lyme disease: case report [in Turkish]. İnönü Üniversitesi Tip Fakültesi Dergisi 2011;18:122-5.

7. Bolognia JL, Jorizzo JL, Rapini RP, Espana A. Figurate erythemas. Dermatology. St Louis: Mosby; 2003: 277-86.

8. Evans SE, Karaduman A. Eritemli dermatozlar [in Turkish]. Turk J Dermatol 2009;3:55-62.

9. Utaş S, Kardag Y, Doganay M. The evaluation of Lyme serology in patients with symptoms which may be related with Borrelia burgdorferi [in Turkish]. Mikrobiyoloji Bulteni 1994;28:106-12.

10. Aguero-Rosenfeld ME, Wang G, Schwartz I, Wormser GP. Diagnosis of lyme borreliosis. Clin Microbiol Rev 2005;18:484-509.

11. DePietropaolo DL, Powers JH, Gill JM, Foy AJ. Diagnosis of lyme disease. Am Fam Physician 2005;72:297-304.

12. Anlar FY, Durlu Y, Aktan G, et al. Clinical characteristics of Lyme disease in 12 cases [in Turkish]. Mikrobiyol Bul 2003;37:255-9.

13. Koksak I, Saltoğlu N, Bingul T, Ozturk H. A case of Lyme disease [in Turkish]. Ankem Dergisi 1990;4:284.

14. Gargili A. Lyme disease: factors and epidemiology. II. Proceedings of Turkey Zoonotic Diseases Symposium; 2008 Nov 27-28. Ankara: Program ve Bildiri Kitabi; s:89-92.

15. Kiliç S. Lyme disease: the pathogen and epidemiology [in Turkish]. Turkiye Klinikleri J Infect Dis Spec Top 2014;7:2941. 